Supporting Information

\title{
Electrochemical Driven Phase Segregation Enabled Dual-ion Removal Battery Deionization Electrode
}

Wenfei Wei ${ }^{\ddagger}$ Xuezhen Feng $\$$, Ranhao Wang, Renji Zheng, Dazhong Yang, Hong Chen*

Shenzhen Key Laboratory of Interfacial Science and Engineering of Materials, State Environmental Protection Key Laboratory of Integrated Surface Water-Groundwater Pollution Control, Guangdong Provincial Key Laboratory of Soil and Groundwater

Pollution Control, School of Environmental Science and Engineering, Southern University of Science and Technology, Shenzhen 518055, China.

E-mail: chenh3@sustech.edu.cn 


\section{EXPERIMENTAL SECTION}

Materials. N-methyl-2-pyrrolidone (NMP) (Aladdin, 99.5 \%), $\mathrm{NaCl}$ (Aladdin, 99.5\%), $\mathrm{CaCl}_{2}$ (Aladdin, $96.0 \%$ ), $\mathrm{MgCl}_{2}$ (Aladdin, $99.0 \%$ ), $\mathrm{KCl}$ (Aladdin, $99.9 \%$ ), $\mathrm{Bi}$ (Aladdin, $99.9 \%$ ), $\mathrm{Bi}\left(\mathrm{NO}_{3}\right)_{3} \cdot 5 \mathrm{H}_{2} \mathrm{O}$ (Aladdin, $99.0 \%$ ), titanium butoxide (Aladdin, 99.0 \%), $\mathrm{H}_{2} \mathrm{O}_{2}(30.0 \mathrm{wt} \%$ ), ammonia solution (25.0-28.0 \%), citric acid (Aladdin, 99.5 \%), $\mathrm{NH}_{4} \mathrm{H}_{2} \mathrm{PO}_{4}$ (Aladdin, $98.0 \%$ ), $\mathrm{NaNO}_{3}$ (Aladdin, $99.0 \%$ ), ethylene glycol (Aladdin, $99.5 \%$ ). Natural seawater from the Shenzhen bay was fetched at $\mathrm{N} 22^{\circ} 31^{\prime}$ and $\mathrm{E}$ $113^{\circ} 59^{\prime}$. The seawater was directly used as the feedwater after filtration with 0.45 um filter paper.

Material Synthesis. For preparation of $\mathrm{NaBi}_{3} \mathrm{O}_{4} \mathrm{Cl}_{2}$, a mixture of $\mathrm{NaCl}, \mathrm{BiOCl}$ and $\mathrm{Bi}_{2} \mathrm{O}_{3}$ with a mole ratio 1:1:1 was ground and loaded into fused-silica tubes, which were sealed under $10^{-3} \mathrm{~Pa}$ atmosphere and then placed in a temperature-controlled furnace. The samples were heated to $800{ }^{\circ} \mathrm{C}$ in $12 \mathrm{~h}$ and kept at that temperature for 5 days, then cooled at a rate of $5{ }^{\circ} \mathrm{C} \mathrm{h}^{-1}$ to $200{ }^{\circ} \mathrm{C}$, and finally cooled down to room temperature.

$\mathrm{BiOCl}$ was synthesized by a hydrothermal method. First, $1.0 \mathrm{~g} \mathrm{Bi}\left(\mathrm{NO}_{3}\right)_{3} \cdot 5 \mathrm{H}_{2} \mathrm{O}$ and $0.3 \mathrm{~g} \mathrm{NaCl}$ were dispersed in $75 \mathrm{~mL}$ distilled water at room temperature with continuous stirring. $1 \mathrm{M} \mathrm{NaOH}$ solution was used to adjust the acidic solution to neutral $\mathrm{pH}$. The mixture solution was stirred for $1 \mathrm{~h}$ and then poured into a $100 \mathrm{~mL}$ a Teflon-lined stainless autoclave. The autoclave was heated at $160{ }^{\circ} \mathrm{C}$ for $24 \mathrm{~h}$ under autogenous pressure, and then air-cooled to room temperature. 
$\mathrm{NaTi}_{2}\left(\mathrm{PO}_{4}\right)_{3} @ \mathrm{C}$ was prepared via a sol-gel reaction method. $3.4 \mathrm{~g}$ titanium butoxide was added to a solution containing $40 \mathrm{~mL} \mathrm{H}_{2} \mathrm{O}_{2}$ and $15 \mathrm{~mL}$ ammonia solution. $4.0 \mathrm{~g}$ Citric acid was then added. After stirring for $5 \mathrm{~min}$, the $10 \mathrm{~mL} \mathrm{NH} \mathrm{H}_{2} \mathrm{PO}_{4}(1.7 \mathrm{~g})$ and $\mathrm{NaNO}_{3}(0.4 \mathrm{~g})$ solution were added to the above solution, which was then stirred at 140 ${ }^{\circ} \mathrm{C}$ for $4 \mathrm{~h}$ and a precursor was obtained. The final product was obtained by pyrolysis of the precursor at $800^{\circ} \mathrm{C}$ for $10 \mathrm{~h}$ in argon.

Electrochemical Experiments. The electrode slurry was prepared by mixing $0.7 \mathrm{~g}$ electrode materials, $0.2 \mathrm{~g}$ acetylene black and $0.1 \mathrm{~g}$ polyvinylidene difluoride (PVDF) in $9.0 \mathrm{~mL}$ NMP. The circular carbon cloth with a diameter of $1.0 \mathrm{~cm}$ was used as the current collector. The obtained slurry was coated onto carbon cloth and dried at $120{ }^{\circ} \mathrm{C}$ for $12 \mathrm{~h}$. CV was conducted using a three-electrode system on a potentiostat (LviumN-Stat, lvium technologies B.V.). The three-electrode setup composed of the active material as a working electrode, a platinum wire as the counter electrode, and a SCE as the reference electrode, respectively. $0.5 \mathrm{M} \mathrm{NaCl}, 0.02 \mathrm{M} \mathrm{NaCl}$ and Shenzhen bay seawater were used as electrolytes. The galvanostatic charge/discharge of the $\mathrm{NaBi}_{3} \mathrm{O}_{4} \mathrm{Cl}_{2}$ electrode in the same three-electrode system was conducted using a battery cycler (CT2001A, LAND) at different current densities. The volume of electrolytes was controlled to be $20 \mathrm{~mL}$. EIS measurement was conducted in the frequency range of $10^{5}$ $10^{-2} \mathrm{~Hz}$

Characterization. PXRD was characterized with a $9 \mathrm{~kW}$ Rigaku SmartLab machine with $\mathrm{Cu} \mathrm{K} \alpha$ radiation $(\lambda=1.5406 \AA)$. The scanning speed was $3^{\circ} \mathrm{min}^{-1}$ and the step 
size were $0.02^{\circ}$ per step. In order to investigate the electrode's phase changes during discharging/charging process, in-situ XRD analysis was performed. The scanning speed was $5^{\circ} \min ^{-1}$, and the step size was $0.02^{\circ}$. The electrode's morphology was collected with a ZEISS Merlin SEM operated at $5 \mathrm{kV}$. TEM and EDS were obtained on an FEI Talos F200X equipped with an EDS operated at $200 \mathrm{kV}$. High-angle annular dark-field scanning transmission electron microscope (HAADF-STEM) and EDS elemental analysis were performed on an FEI Titan Themis apparatus with an X-FEG electron gun and a DCOR aberration corrector operating at $300 \mathrm{kV}$. XPS analyses were carried out on a PHI 5000 Versaprobe III spectrometer using a monochromatic Al K(alpha) X-ray source. All XPS spectra were analyzed and fitted using the multipak software and corrected relative to the $\mathrm{C} 1 \mathrm{~s}$ signal at $284.8 \mathrm{eV}$. 
1. Morphology of $\mathrm{NaBi}_{3} \mathrm{O}_{4} \mathrm{Cl}_{2}$

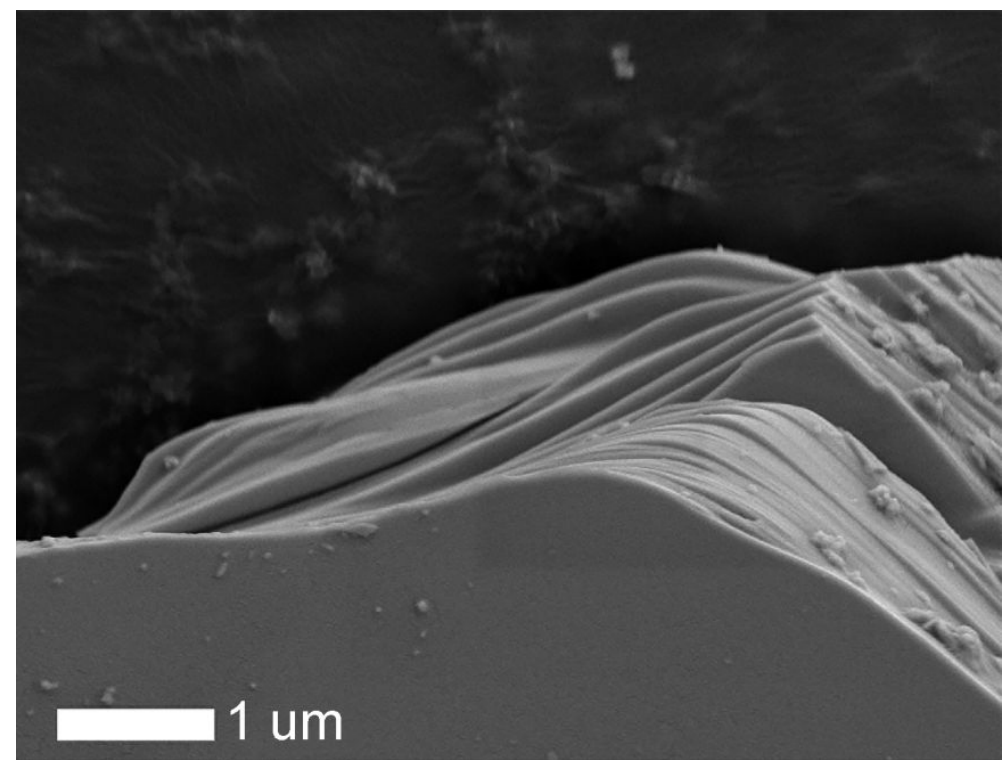

Figure S1. SEM of $\mathrm{NaBi}_{3} \mathrm{O}_{4} \mathrm{Cl}_{2}$ 


\section{Electrochemical performance of $\mathrm{NaBi}_{3} \mathrm{O}_{4} \mathrm{Cl}_{2}$ and $\mathrm{Bi}$ electrodes}

a)

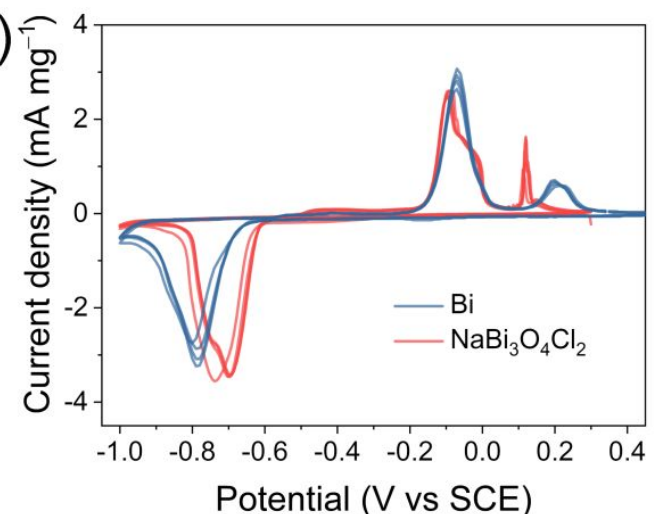

c)

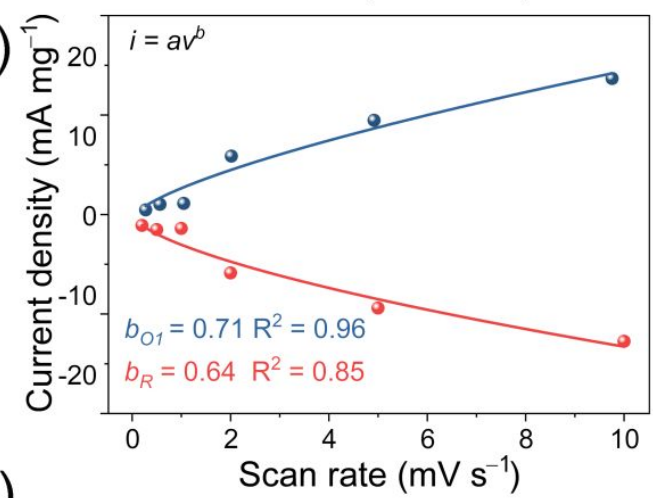

e)

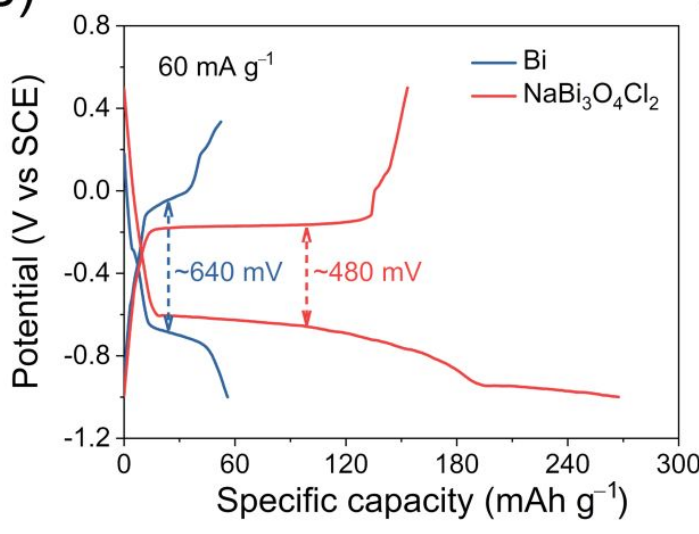

b)

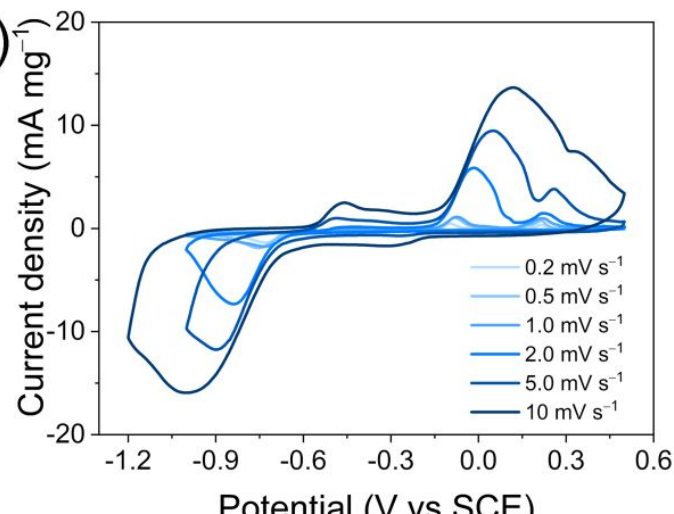

d)

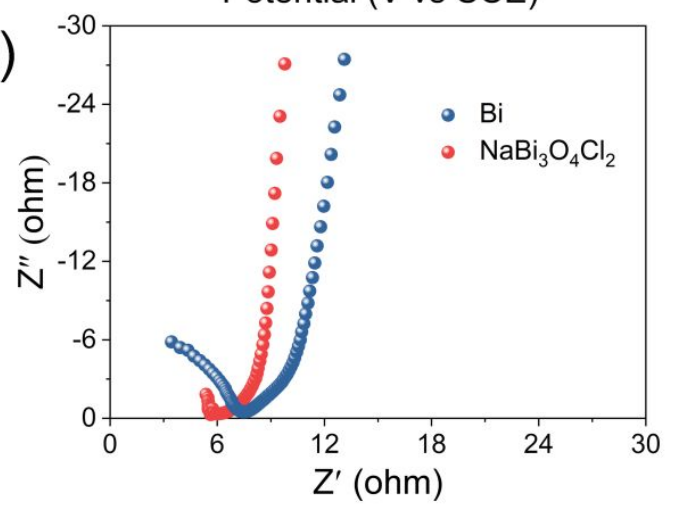

)

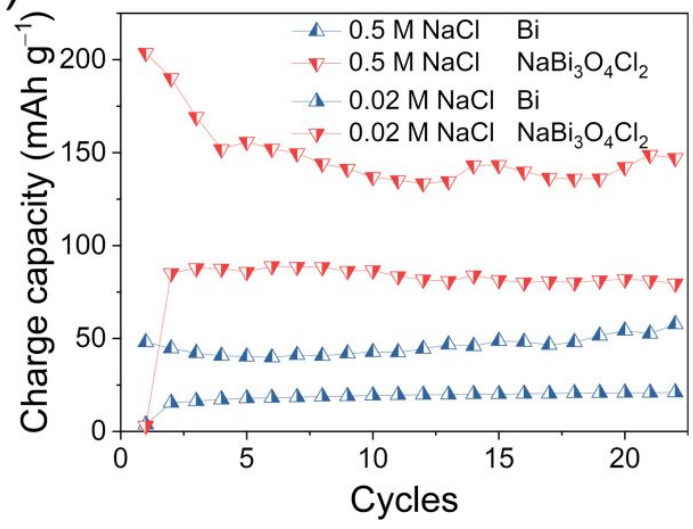

Figure S2. Electrochemical performance of $\mathrm{NaBi}_{3} \mathrm{O}_{4} \mathrm{Cl}_{2}$ and $\mathrm{Bi}$ electrodes. $\mathrm{CV}$ curves a) in $0.5 \mathrm{M} \mathrm{NaCl}$ at $1 \mathrm{mV} \mathrm{s}^{-1}$ and b) in different scan rates. c) $b$-value of Bi electrodes. d) EIS after 5 cycles. e) Typical charge/discharge curves in $0.5 \mathrm{M}$ $\mathrm{NaCl}$ d) Charge capacity retentions at $60 \mathrm{~mA} \mathrm{~g}^{-1}$. 
3. Cycling stability of $\mathrm{NaBi}_{3} \mathrm{O}_{4} \mathrm{Cl}_{2}$ electrode
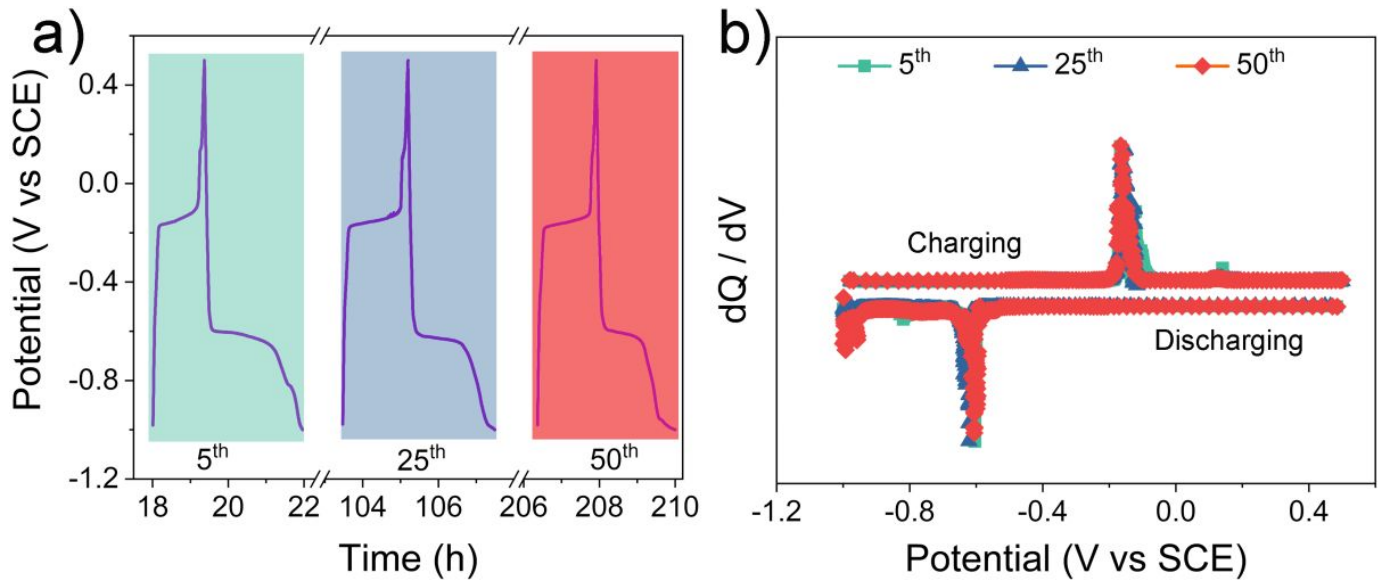

Figure S3. a) Charge/discharge curves. b) Differential capacity curves. 
4. Voltage profiles and crystallographic phase analysis of $\mathrm{NaBi}_{3} \mathrm{O}_{4} \mathrm{Cl}_{2}$ electrode
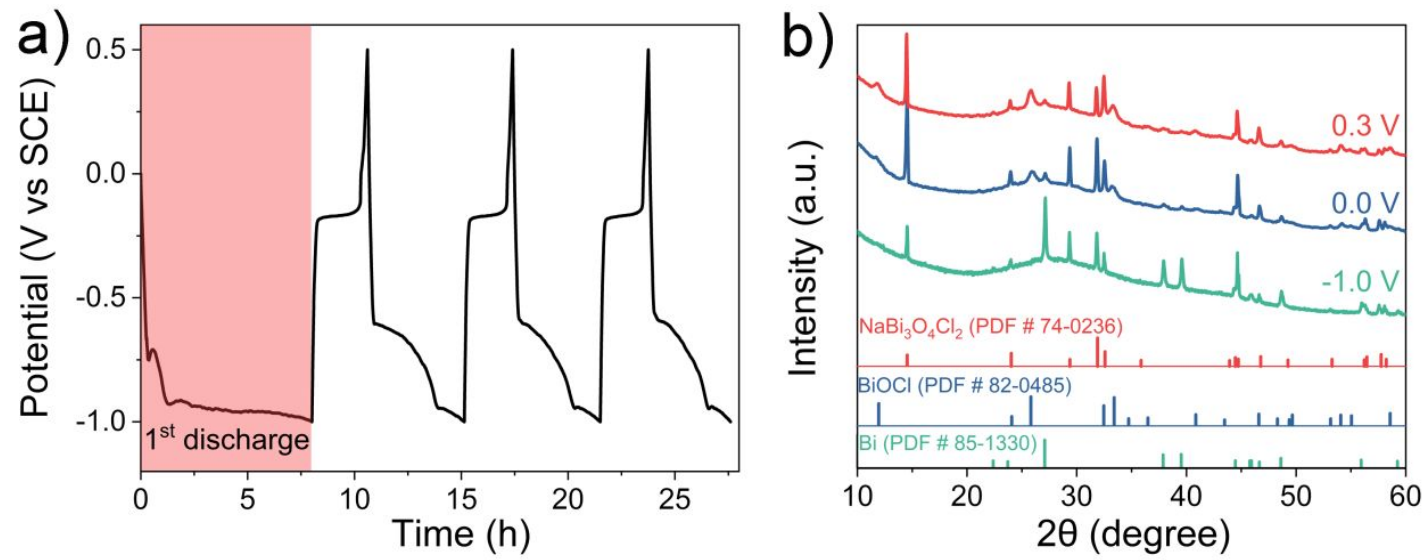

Figure S4. a) Voltage profiles. b) Ex-situ PXRD under different electrochemical potential. 


\section{Structure evolutions of $\mathrm{NaBi}_{3} \mathrm{O}_{4} \mathrm{Cl}_{2}$ and $\mathrm{Bi}$ electrode}
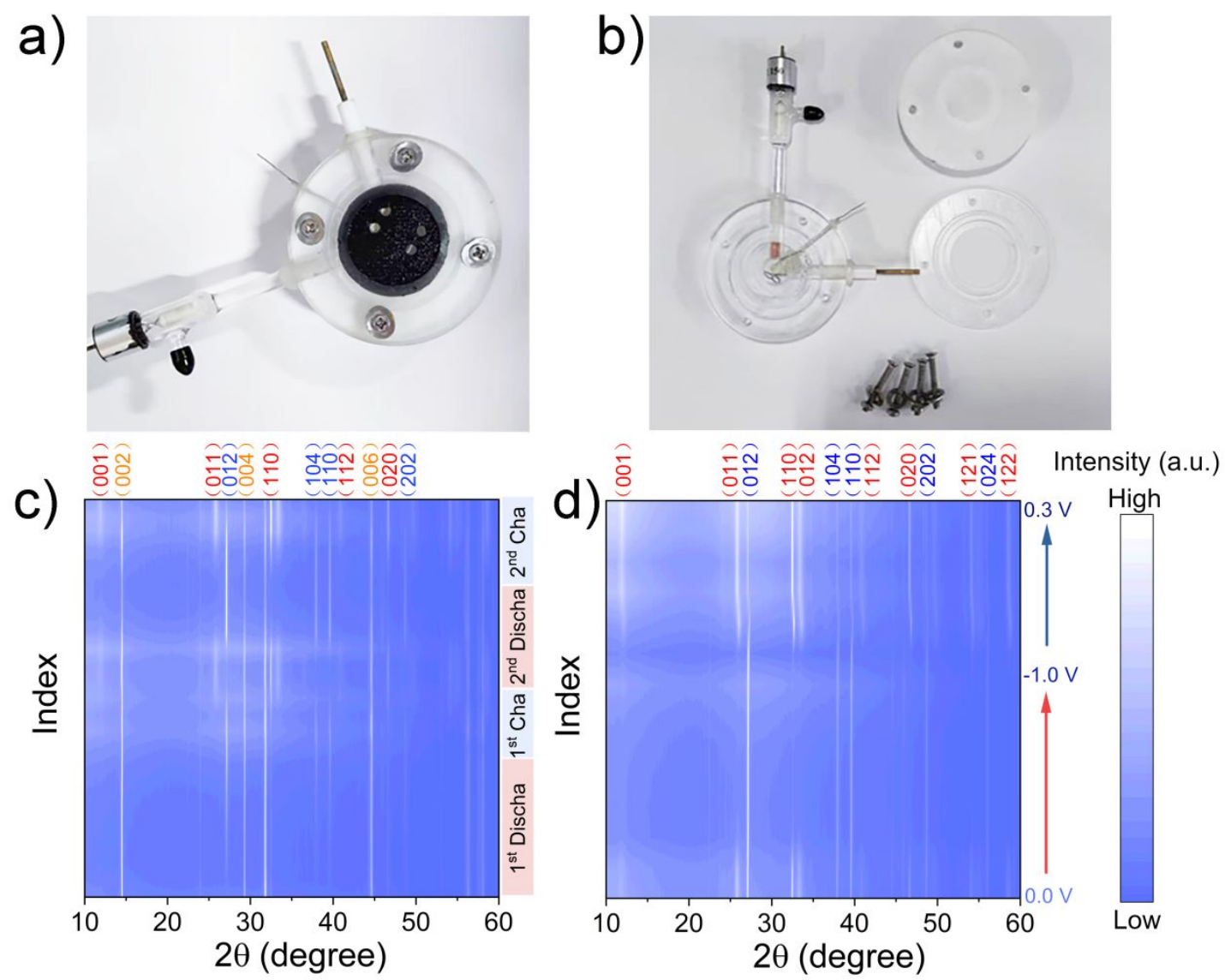

Figure S5. Structure evolution dynamics study with a-b) a home-made three electrodes device for in-situ PXRD data collection. c) In-situ PXRD patterns of $\mathrm{NaBi}_{3} \mathrm{O}_{4} \mathrm{Cl}_{2}$ electrode in the first and second cycle. d) In-situ PXRD patterns of pure $\mathrm{Bi}$ electrode. The orange, red, and blue index is attributed to the corresponding crystallographic diffraction planes in $\mathrm{NaBi}_{3} \mathrm{O}_{4} \mathrm{Cl}_{2}, \mathrm{BiOCl}$, and $\mathrm{Bi}$. 


\section{XPS survey spectrum}

a)

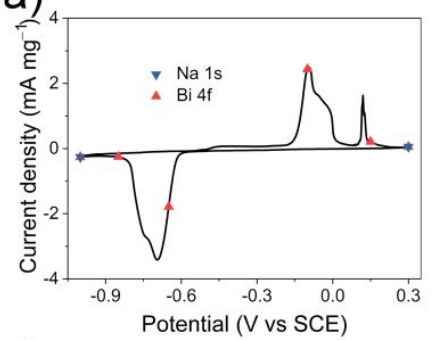

d)

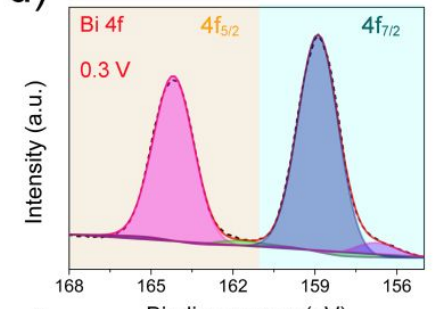

g)

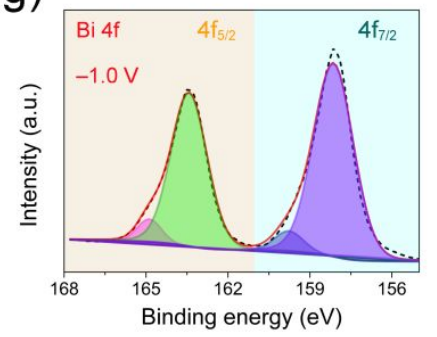

b)

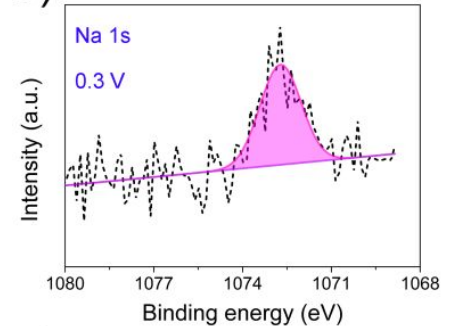

e)
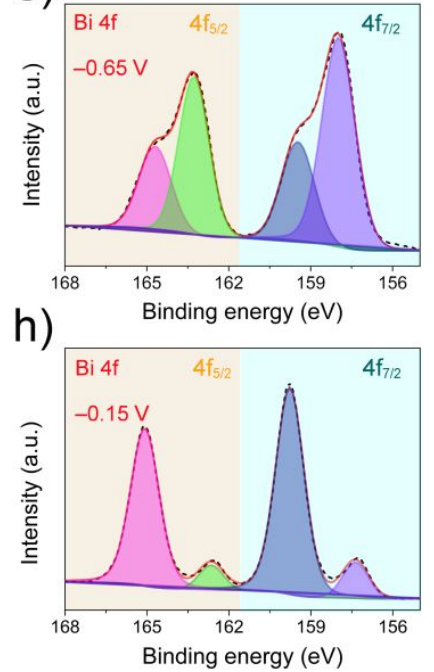

c)

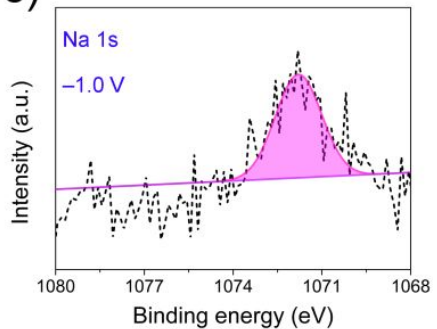

f)

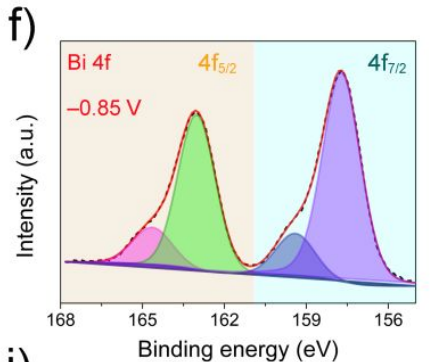

i)

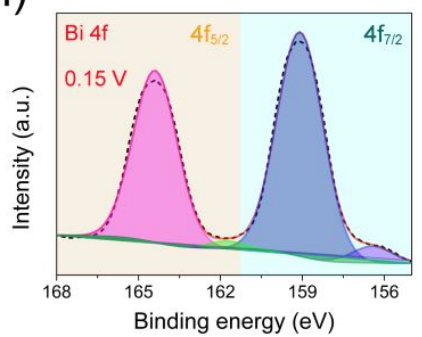

Figure S6. High-resolution Na 1s and Bi 4f XPS spectra at different potentials. a) $6^{\text {th }}$ CV curve of $\mathrm{NaBi}_{3} \mathrm{O}_{4} \mathrm{Cl}_{2}$. b) and c) $\mathrm{Na}$ 1s for $\mathrm{NaBi}_{3} \mathrm{O}_{4} \mathrm{Cl}_{2}$. d-i) Bi $4 \mathrm{f}_{5 / 2}$ and $4 \mathrm{f}_{7 / 2}$ for $\mathrm{NaBi}_{3} \mathrm{O}_{4} \mathrm{Cl}$.

Note: As shown in Figure S6, the peaks located at $1072 \mathrm{eV}$ belong to $\mathrm{Na}^{+}$are observed in the charged and discharged electrodes. The peaks of $\mathrm{Bi}^{3+}(164 \mathrm{eV}$ and $158 \mathrm{eV}$ ) gradually weaken during the discharging process, and strengthen during the charging process. As a contrast, the peaks of $\mathrm{Bi}^{0}(163 \mathrm{eV}$ and $157 \mathrm{eV})$ strengthen during the discharging process and weaken during the charging process. 
7. Composition analysis of charged $\mathrm{NaBi}_{3} \mathrm{O}_{4} \mathrm{Cl}_{2}$ electrode

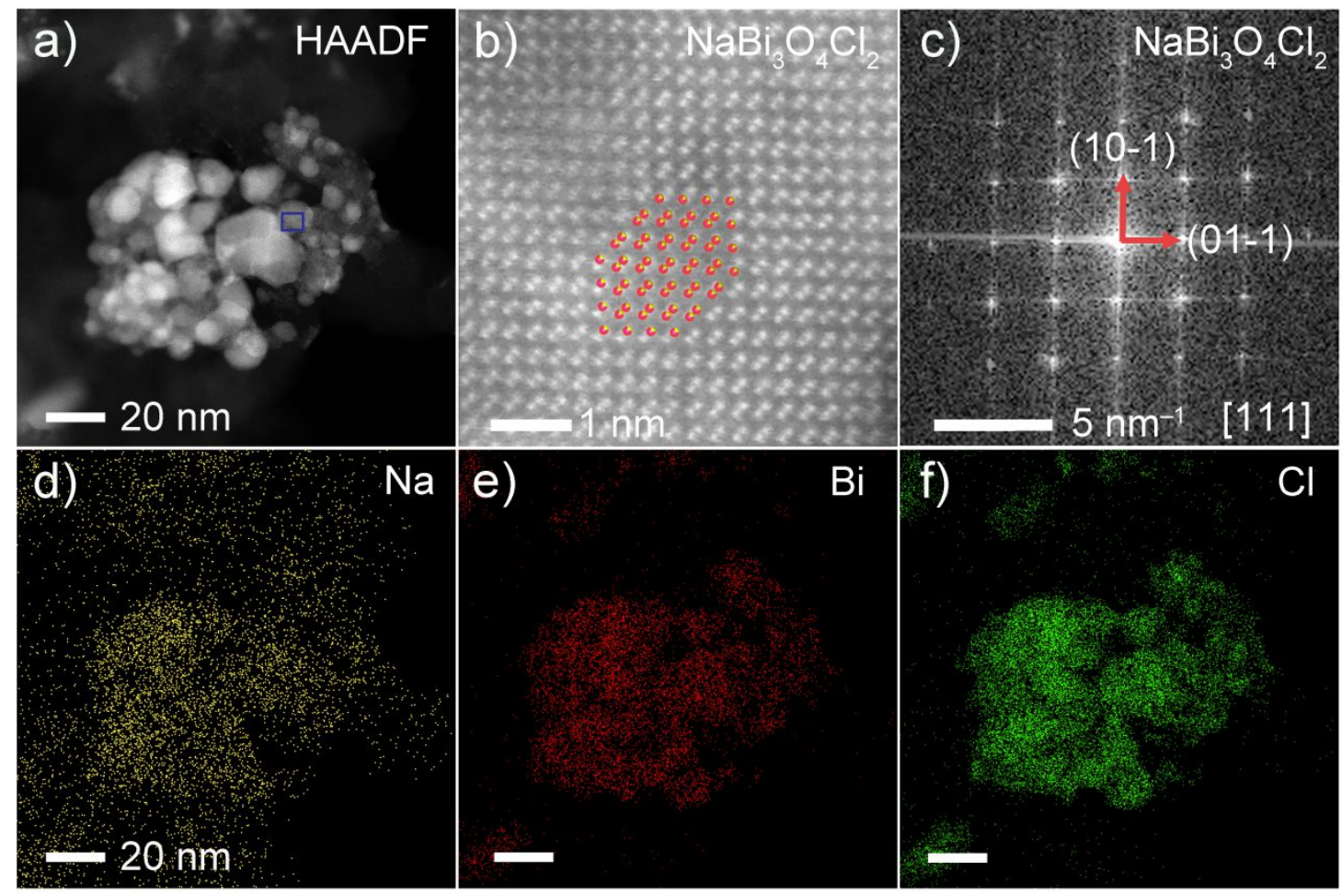

Figure S7. Characterization of the charged $\mathrm{NaBi}_{3} \mathrm{O}_{4} \mathrm{Cl}_{2}$. a) TEM image, b) Atomicresolution STEM image. c) FFT pattern. d) TEM-EDS elemental mapping of $\mathrm{Na}$, $\mathrm{Bi}$ and $\mathrm{Cl}$ in the charged electrode. 


\section{Ions removal capacity of $\mathrm{NaBi}_{3} \mathrm{O}_{4} \mathrm{Cl}_{2}$}

For electrochemical desalination, the electrodes' charge is compensated by the ionic charge $^{1}$. Consequently, the amount of ion removed from a feed-water stream depends on the electrode's invested charge, and it is convenient to normalize the desalination capacity to the electrode material mass. First, the theoretical charge capacity of $\mathrm{NaBi}_{3} \mathrm{O}_{4} \mathrm{Cl}_{2}$ and $\mathrm{BiOCl}$ were calculated by equation $\mathrm{S}^{2}$.

$$
C_{\text {Theoretical }}=\frac{n \times F}{3.6 \times M}
$$

Where $n$ is the number of transferred electrons, $\mathrm{F}$ is the Faraday constant, $M$ is the molar mass. Thus, we calculated the $\mathrm{C}_{\text {theor }}$ of $\mathrm{NaBi}_{3} \mathrm{O}_{4} \mathrm{Cl}_{2}$ and $\mathrm{BiOCl}$ are $307 \mathrm{mAh} \mathrm{g}^{-1}$ and $309 \mathrm{mAh} \mathrm{g}^{-1}$, respectively. Then, the specific number of ions removed was confirmed by equation $\mathrm{S} 2$ :

$$
x=\frac{n \times C_{\text {Specific }}}{C_{\text {Theoretical }}}
$$

Where $n$ is the theoretical number of ions that could react with per material, for $\mathrm{NaBi}_{3} \mathrm{O}_{4} \mathrm{Cl}_{2}$, the $n_{\mathrm{Na}^{+}}=1, n_{\mathrm{Cl}^{-}}=2$; For $\mathrm{BiOCl}$, the $n_{\mathrm{Cl}^{-}}=1$. The specific capacity is equal to the specific charge capacity. Finally, the ions removal capacity Q ( $\left.\mathrm{mg} \mathrm{g}^{-1}\right)$ can be obtained by equation S3:

$$
Q=1000 \times \frac{x \times M_{\text {ion }}}{M_{\text {material }}}
$$

Where $M_{i o n}$ is the atomic mass of the ion, $M_{\text {material }}$ is the molecular mass of material. According to the in-situ PXRD analysis, both $\mathrm{NaBi}_{3} \mathrm{O}_{4} \mathrm{Cl}_{2}$ and $\mathrm{BiOCl}$ were generated in the charging process. Through XPS and EDS quantitative analysis (Figure S8 and Table $\mathrm{S} 1$ ), the $\mathrm{NaBi}_{3} \mathrm{O}_{4} \mathrm{Cl}_{2}$ and $\mathrm{BiOCl}$ account for $\sim 56 \mathrm{wt} \%$ and $\sim 44 \mathrm{wt} \%$ of 
the charged electrode (after 50 cycles), respectively. Based on the equations S2-3, we can calculate the ions removal capacity of $\mathrm{NaBi}_{3} \mathrm{O}_{4} \mathrm{Cl}_{2}$ electrode in charging progress.
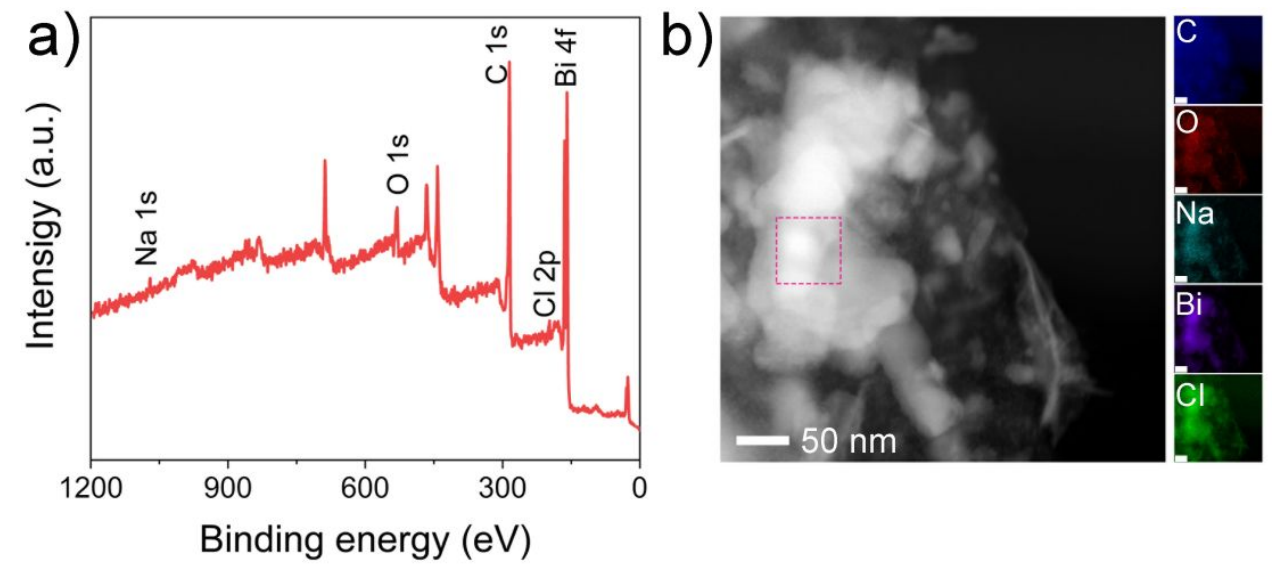

Figure S8. Composition analysis of charged $\mathrm{NaBi}_{3} \mathrm{O}_{4} \mathrm{Cl}_{2}$ electrode. a) XPS spectra. b) EDS analysis.

Table S1 Element analysis of charged $\mathrm{NaBi}_{3} \mathrm{O}_{4} \mathrm{Cl}_{2}$ electrode

\begin{tabular}{llllll}
\hline & $\mathrm{Na}(\mathrm{At} \%)$ & $\mathrm{Bi}(\mathrm{At} \%)$ & $\mathrm{O}(\mathrm{At} \%)$ & $\mathrm{Cl}(\mathrm{At} \%)$ & $\mathrm{C}(\mathrm{At} \%)$ \\
\hline XPS & 0.6 & 3.2 & 4.4 & 2.9 & 88.9 \\
EDS & 0.4 & 4.2 & 8.3 & 15.4 & 71.7 \\
\hline
\end{tabular}


9. Characterization of the as-synthesized $\mathrm{NaTi}_{2}\left(\mathrm{PO}_{4}\right)_{3} @ \mathrm{C}$

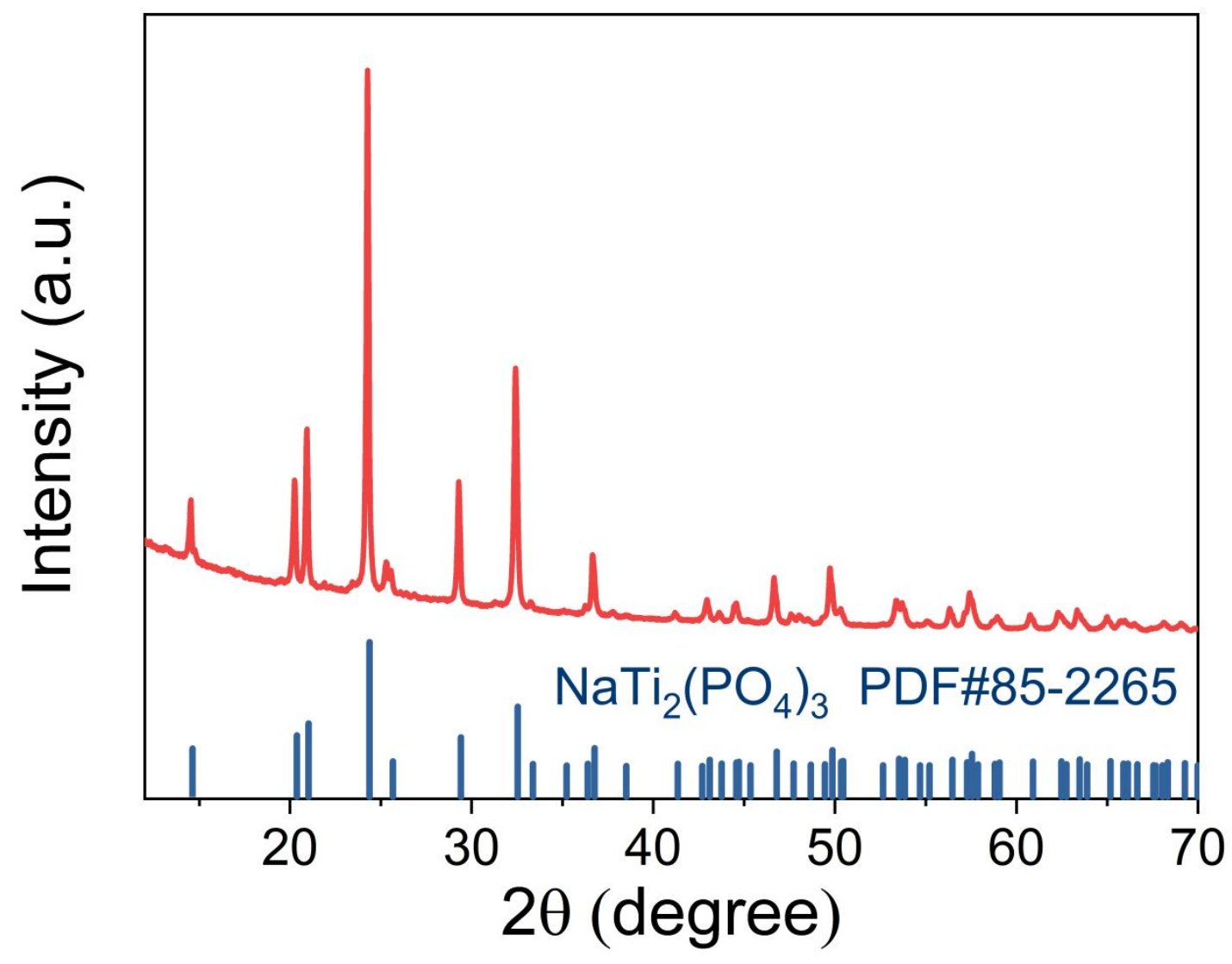

Figure S9. PXRD pattern of $\mathrm{NaTi}_{2}\left(\mathrm{PO}_{4}\right)_{3} @ \mathrm{C}$ 
10. Cycling performance of $\mathrm{NaBi}_{3} \mathrm{O}_{4} \mathrm{Cl}_{2}$ electrode in seawater
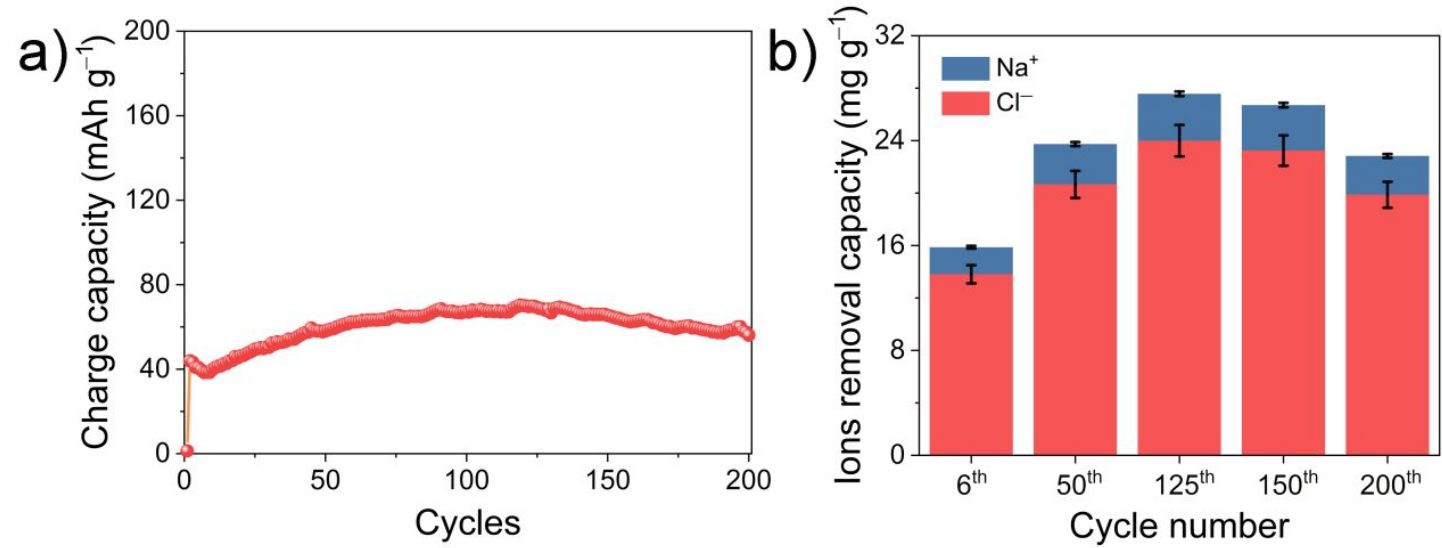

Figure S10. Ions removal performance of $\mathrm{NaBi}_{3} \mathrm{O}_{4} \mathrm{Cl}_{2}$ electrodes in seawater. a) Charge capacity retention at $60 \mathrm{~mA} \mathrm{~g}^{-1}$ and b) Ions removal capacity of $\mathrm{NaBi}_{3} \mathrm{O}_{4} \mathrm{Cl}_{2}$ electrodes. 
11. Cycling stability of $\mathrm{NaBi}_{3} \mathrm{O}_{4} \mathrm{Cl}_{2}$ electrode in seawater
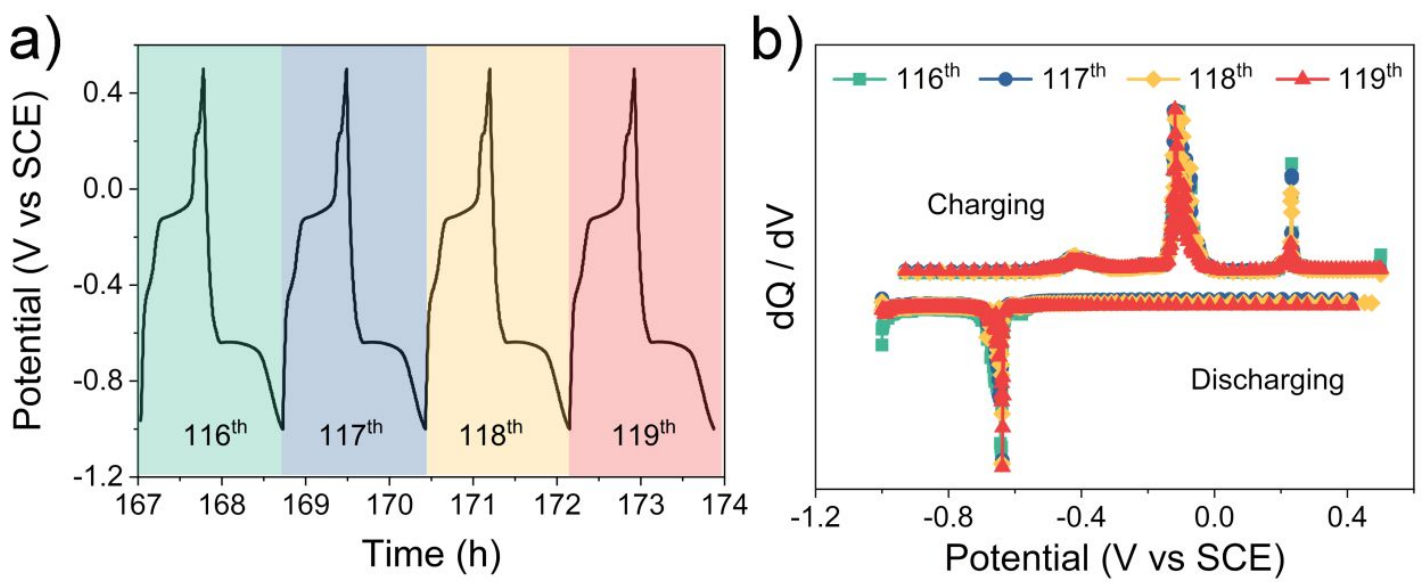

Figure S11. a) Charge/discharge curves. b) Differential capacity curves.

Note: Charge/discharge curves of $\mathrm{NaBi}_{3} \mathrm{O}_{4} \mathrm{Cl}_{2}$ electrode in seawater were conducted using a three-electrode system. The three-electrode setup was composed of $\mathrm{NaBi}_{3} \mathrm{O}_{4} \mathrm{Cl}_{2}$ electrode as a working electrode, a platinum wire as the counter electrode, and a saturated calomel electrode (SCE) as the reference electrode, respectively. 
12. Table $\mathbf{S 2}$ Comparison of the desalination performance of different bismuth-based materials $^{\alpha}$

\begin{tabular}{|c|c|c|c|c|c|}
\hline Materials & Operation & Current & Initial salt & Electro adsorption or & Ref \\
\hline & voltage & density & concentration & discharge capacity & \\
\hline \multirow[t]{4}{*}{$\mathrm{NaBi}_{3} \mathrm{O}_{4} \mathrm{Cl}_{2}$} & $-1.0-0.5 \mathrm{~V}$ & $60 \mathrm{~mA} \mathrm{~g}^{-1}$ & $0.5 \mathrm{M} \mathrm{NaCl}$ & $8.7 \mathrm{mg} \mathrm{g}^{-1}\left(\mathrm{Na}^{+}\right)$ & This \\
\hline & (vs SCE) & & & $58.4 \mathrm{mg} \mathrm{g}^{-1}\left(\mathrm{Cl}^{-}\right)$ & work \\
\hline & $-1.0-0.5 \mathrm{~V}$ & $60 \mathrm{~mA} \mathrm{~g}^{-1}$ & Natural seawater & $2.9 \mathrm{mg} \mathrm{g}^{-1}\left(\mathrm{Na}^{+}\right)$ & \\
\hline & (vs SCE) & & & $19.8 \mathrm{mg} \mathrm{g}^{-1}\left(\mathrm{Cl}^{-}\right)$ & \\
\hline \multirow[t]{2}{*}{$\mathrm{Bi}$} & $-1.0-0.5 \mathrm{~V}$ & $60 \mathrm{~mA} \mathrm{~g}^{-1}$ & $0.5 \mathrm{M} \mathrm{NaCl}$ & $22.9 \mathrm{mg} \mathrm{g}^{-1}\left(\mathrm{Cl}^{-}\right)$ & \\
\hline & (vs SCE) & & & & \\
\hline $\mathrm{Bi}$ & $0-1.1 \mathrm{~V}$ & $1 \mathrm{~mA} \mathrm{~cm}^{-2}$ & $0.6 \mathrm{M} \mathrm{NaCl}$ & $0.27 \mathrm{mAh} \mathrm{cm}^{-2}\left(\mathrm{Cl}^{-}\right)$ & 3 \\
\hline $\mathrm{Bi}$ & $-1.4-1.5 \mathrm{~V}$ & $100 \mathrm{~mA} \mathrm{~g}^{-1}$ & $1 \mathrm{M} \mathrm{NaCl}$ & $41.7 \mathrm{mg} \mathrm{g}^{-1}\left(\mathrm{Cl}^{-}\right)$ & 4 \\
\hline $\mathrm{Bi}$ & $1.2 \mathrm{~V}$ & & $500 \mathrm{mg} \mathrm{L}^{-1} \mathrm{NaCl}$ & $33.8 \mathrm{mg} \mathrm{g}^{-1}\left(\mathrm{Cl}^{-}\right)$ & 5 \\
\hline
\end{tabular}

${ }^{\alpha} \mathrm{The} \mathrm{Cl}^{-}$removal capacity of reported works was calculated by equation S4.

$$
Q_{C l^{-}}=M_{C l} \times \frac{Q_{\text {total }}}{M_{\text {NaCl }}}
$$

Where $\mathrm{M}_{\mathrm{Cl}}$ is the atomic mass of the $\mathrm{Cl}, \mathrm{M}_{\mathrm{NaCl}}$ is the molecular mass of $\mathrm{NaCl}$. 


\section{Reference}

1. Srimuk, P.; Su, X.; Yoon, J.; Aurbach, D.; Presser, V., Charge-transfer materials for electrochemical water desalination, ion separation and the recovery of elements. Nat. Rev. Mater. 2020, 5 (7), 517-538.

2. Schon, T. B.; Mcallister, B. T.; Li, P. F.; Seferos, D. S., The rise of organic electrode materials for energy storage. Chem. Soc. Rev. 2016, 45 (22), 6345-6404.

3. Nam, D. H.; Choi, K. S., Bismuth as a New Chloride-Storage Electrode Enabling the Construction of a Practical High Capacity Desalination Battery. J. Am. Chem. Soc. 2017, 139 (32), 11055-11063.

4. Chen, F.; Huang, Y.; Guo, L.; Sun, L.; Wang, Y.; Yang, H. Y., Dual-ions electrochemical deionization: A desalination generator. Energ. Environ. Sci. 2017, 10 (10), 2081-2089.

5. Chang, J.; Duan, F.; Su, C.; Li, Y.; Cao, H., Removal of chloride ions using a bismuth electrode in capacitive deionization (CDI). Environ Sci-Wat Res. 2020, 6 (2), 373-382. 